\title{
Desafios do modelo de desenvolvimento agrícola do estado de Mato Grosso do Sul: uma proposta para o desenvolvimento sustentável
}

\author{
Challenges of the agricultural development model of the state of Mato Grosso \\ do Sul: a proposal for sustainable development
Desafíos del modelo de desarrollo agrícola del estado de Mato Grosso do Sul: una propuesta para el desarrollo sostenible

\author{
Everton Castelão Tetila ${ }^{1}$ \\ José Laerte Cecílio Tetila² \\ Hemerson Pistori ${ }^{3}$ \\ Maria Angélica Biroli Ferreira da Silva ${ }^{4}$
}

Recebido em: 05/03/2019. Revisado e aprovado em: 31/10/2019. Aceito em: 30/01/2020

DOI: http://dx.doi.org/10.20435/inter.v21i3.2430

\begin{abstract}
Resumo: Este artigo apresenta uma discussão sobre o atual modelo de desenvolvimento agrícola das terras cultivadas no estado de Mato Grosso do Sul. São discutidas as causas das transformações ambientais e os meios de produção que geram várias implicações sobre povos indígenas, agricultores familiares e biomas já fragilizados, além da questão da saúde humana e da segurança alimentar. Por fim, o artigo apresenta uma proposta, baseada em alternativas ecologicamente corretas, rumo à construção da sustentabilidade ambiental e do bem-estar social do estado de Mato Grosso do Sul.
\end{abstract}

Palavras-chave: agroecologia; agricultura de precisão; corredores ecológicos; desenvolvimento sustentável.

Abstract: This paper presents a discussion about the current model of agricultural development of cultivated lands in the state of Mato Grosso do Sul. We discuss the causes of environmental transformations and the means of production that generate various implications on indigenous peoples, family farmers, and already fragile biomes, as well as the issue of human health and food safety. Finally, the article presents a proposal, based on ecologically correct alternatives, towards the construction of environmental sustainability and social welfare of the state of Mato Grosso do Sul.

Keywords: agroecology; precision agriculture; ecological corridors; sustainable development.

Resumen: Este artículo presenta una discusión sobre el actual modelo de desarrollo agrícola de las tierras cultivadas en el estado de Mato Grosso do Sul. Se discuten las causas de las transformaciones ambientales y los medios de producción que generan varias implicaciones sobre pueblos indígenas, agricultores familiares y biomas ya fragilizados, además de la cuestión de la salud humana y la seguridad alimentaria. Por último, el artículo presenta una propuesta, basada en alternativas ecológicamente correctas, hacia la construcción de la sostenibilidad ambiental y el bienestar social del estado de Mato Grosso do Sul.

Palabras clave: agroecología; agricultura de precisión; corredores ecológicos; desenvolvimiento sustentable.

\section{INTRODUÇÃO}

O estado de Mato Grosso do Sul localiza-se na região Centro-Oeste do Brasil, sendo considerado um importante estado produtor de soja, milho, açúcar, celulose e carne bovina. Essa região caracteriza-se principalmente pelos elevados índices de produção agropecuária direcionada à exportação, decorrente de seus solos férteis, com extensas superfícies planas e clima tropical e subtropical favoráveis, aliados a grandes investimentos na moderna tecnologia agropecuária.

\footnotetext{
${ }^{1}$ Universidade Federal da Grande Dourados (UFGD), Dourados, Mato Grosso do Sul, Brasil.

${ }^{2}$ Assembleia Legislativa do Estado de Mato Grosso do Sul, Campo Grande, Mato Grosso do Sul, Brasil.

${ }^{3}$ Universidade Católica Dom Bosco (UCDB), Campo Grande, Mato Grosso do Sul, Brasil.

${ }^{4}$ Universidade Federal de Mato Grosso do Sul (UFMS), Campo Grande, Mato Grosso do Sul, Brasil.
} 
Além de abastecer a indústria alimentícia, o setor agropecuário também contribui para o abastecimento de outras indústrias, tais como farmacêutica, cosmética, têxtil e sucroenergética, sendo considerado uma das principais bases da economia brasileira.

Nos últimos anos, a produção de grãos tem alcançado um respaldo econômico importante para a balança comercial brasileira. "A estimativa da produção de grãos, para a safra 2018/19, é de 238,9 milhões de toneladas. O crescimento deverá ser de 4,9\% ou 11,2 milhões de toneladas acima da safra anterior. A área plantada está prevista em 62,9 milhões de hectares [Mha]. 0 crescimento calculado é de 1,9\%, comparando-se com a safra 2017/18" (COMPANHIA NACIONAL DE ABASTECIMENTO [CONAB], 2019). Entretanto, as áreas cobertas por plantações mais que dobraram no Brasil entre 2000 e 2014 (de 26,0 Mha em 2000 para 46,1 Mha em 2014), e pelo menos $20 \%$ dessa expansão agrícola ocorreu sobre vegetação nativa. Nesse período, a conversão de áreas naturais em plantações foi maior no Cerrado: quase 2,5 vezes mais que na Floresta Amazônica (ZALLES et. Al., 2000).

A participação dos pesticidas na composição dos custos operacionais, em todos os levantamentos realizados pela Conab (2016), apresentou incremento médio de 4,41\% entre os anos-safra de 2007/08 a 2015/16, o maior observado entre os insumos analisados (CONAB, 2016). Esse aumento ao longo do tempo pode provocar várias perturbações ao meio ambiente, como: seleção de indivíduos resistentes, redução de compostos orgânicos e microrganismos, ressurgimento de espécies controladas, surto de pragas de importância secundária, redução da população de insetos polinizadores, efeitos deletérios em animais, acúmulo de resíduos tóxicos no solo e nos alimentos, contaminação da água e da fauna aquática, falhas em programas de erradicação química, além de problemas de ordem econômica e social (PEDIGO, 2001).

Em certos casos, o uso de pesticidas para o controle de doenças, plantas infestantes e pragas pode ser substituído por defensivos agroecológicos - um meio ecologicamente correto de manejo e cultivo de plantas, ausentes de substâncias tóxicas e de baixo impacto ecológico. Nesse seguimento, há casos de sucesso de soluções agroecológicas (produtos e métodos) como alternativa viável ao uso de pesticidas, tais como: inseticidas biológicos - baculovirus (VALICENTE et al., 2009), telenomus podisi Ashmead (COSTA et al., 2017); agentes de biocontrole de doenças em plantas à base de fungos - Trichoderma spp, Paecilomyces spp (BETTIOL et al., 2012); bactérias - Bacillus spp (HECK et al., 2014), Pseudomonas spp (ZAGO; POLLI; RUMJANEK, 2000); bioinseticidas à base de minerais - caulim (SILVA, 2014); e armadilhas biológicas para o controle de pragas - feromônio (VILELA, 1992) e urina bovina (CORREA-FERREIRA; ROGGIA; SEIXAS, 2014).

Um novo paradigma que vem sendo utilizado nos campos de cultivo para aumentar a produção de alimentos e reduzir o impacto ambiental é a Agricultura de Precisão, "um sistema de gerenciamento agrícola baseado na variação espacial e temporal da unidade produtiva e visa ao aumento de retorno econômico, à sustentabilidade e à minimização do efeito ao ambiente" (BRASIL, 2012). As tecnologias de Agricultura de Precisão estão difundindo progressivamente o conhecimento da variabilidade espacial das unidades produtivas em todos os seus aspectos, devido às variações de produtividade, solo, relevo, vegetação e também do histórico de uso. Essas diferenças fazem com que produtores e técnicos tratem cada região da lavoura de modo diferenciado, realocando insumos para que sejam diminuídos os desequilíbrios de acordo com as necessidades e potencialidades de cada área (BERNARDI et al., 2014).

Técnicas de sensoriamento remoto, em que as informações da lavoura são obtidas de forma não destrutiva, rápida e por vezes a distância (satélite, avião ou veículos aéreos não tripulados 
[Vants]), têm sido fundamentais na obtenção e no tratamento dos dados de campo. A radiometria espectral é capaz de identificar a intensidade com que cada material, seja um tipo de solo, seja um tipo de rocha ou de vegetação, reflete a radiação eletromagnética em diferentes comprimentos de onda do espectro. Assim, dados da refletância têm sido associados às características das plantas, como o índice da área foliar, biomassa, porcentagem de cobertura do solo, atividade fotossintética e estresse hídrico (BERNARDI et al., 2014).

$\mathrm{Na}$ agricultura, as propriedades da refletância em cada faixa do espectro eletromagnético podem ser mais bem avaliadas por meio de combinações matemáticas de diferentes bandas espectrais. Essas transformações são medidas da atividade da vegetação, especialmente na região do visível e do infravermelho próximo (Near Infrared - NIR), e são denominadas de índices de vegetação. A escolha do índice de vegetação mais adequado está relacionada às características que se deseja avaliar. Com base nos índices de vegetação, os insumos (corretivos, fertilizantes e defensivos) podem ser aplicados em taxas variáveis nos pontos localizados com problemas, com o uso de arquivos de dados geoespaciais construídos na forma de mapas de recomendação de aplicação (p. ex. shapefile ${ }^{5}$ ), exportados para o maquinário agrícola que utiliza automação baseada em um sistema de posicionamento global (GPS). As tecnologias disponíveis indicam que há potencial para gerar sistemas de recomendação de aplicação de insumos de forma mais eficiente, com alta probabilidade de retorno econômico e baixo impacto ambiental, favorecendo a saúde humana e a segurança alimentar (BERNARDI et al., 2014).

Diante do contexto exposto, este artigo apresenta a dinâmica espaço-temporal da expansão das terras cultivadas no estado de Mato Grosso do Sul e propõe discutir as causas das transformações ambientais, as políticas de uso da terra e os meios de produção que geram várias implicações sobre povos indígenas, agricultores familiares e biomas já fragilizados, além da questão da saúde humana e da segurança alimentar. Uma abordagem baseada em alternativas ecologicamente corretas e iniciativas de preservação é apresentada como proposta para o desenvolvimento sustentável e bem-estar social do estado de Mato Grosso do Sul.

Este artigo está organizado da seguinte forma: a Seção II apresenta a revisão teórica das temáticas abordadas nesta pesquisa, seguida por uma discussão; uma proposta para o desenvolvimento sustentável do estado de Mato Grosso do Sul está descrita na Seção III; conclusões e trabalhos futuros são relatados na Seção IV.

\section{REVISÃO TEÓRICA}

\subsection{Desmatamento do Cerrado em MS}

Apesar da luta mundial em defesa do meio ambiente, o desmatamento das florestas brasileiras tem crescido nos últimos anos, sendo o Brasil considerado o primeiro no ranking de perda líquida de área florestal entre 2010 e 2015 (FOOD AND AGRICULTURE ORGANIZATION OF THE UNITED NATIONS [FAO], 2016). Em Mato Grosso do Sul, o último dado oficial do Ministério do Meio Ambiente, por meio do Plano de Ação para Prevenção e Controle do Desmatamento e das Queimadas no Cerrado (BRASIL, 2014), mostra que já foram desmatados 76\% do Cerrado sul-mato-grossense (Figura 1).

\footnotetext{
${ }^{5}$ Shapefile são arquivos de dados geoespaciais em forma de vetor, utilizados para descrever geometrias, como pontos, linhas e polígonos.
} 
Figura 1 - Área total do bioma e proporções de área desmatada e remanescente em 2010 nos estados que compõem o Cerrado

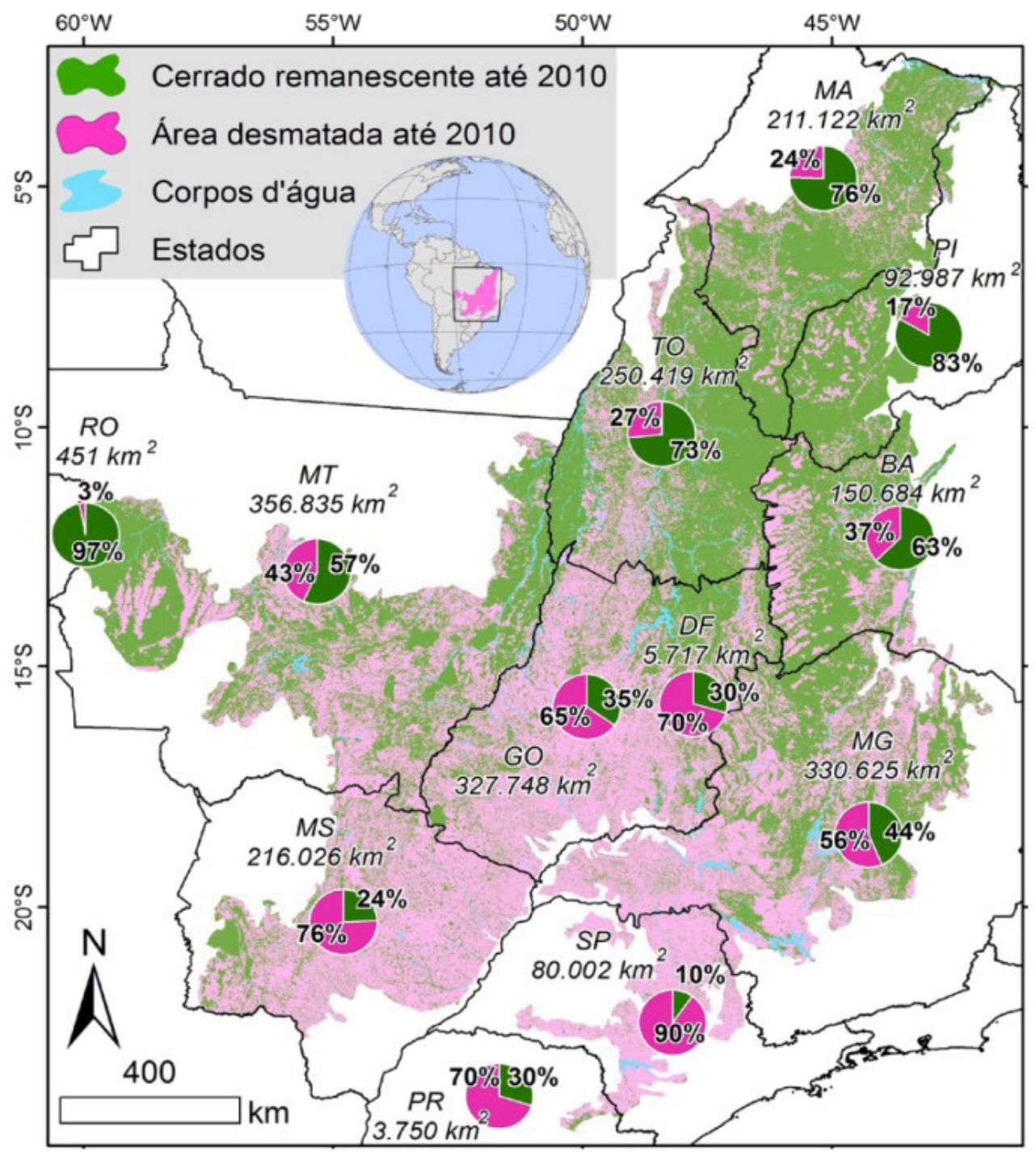

Fonte: Brasil (2014).

Segundo o Plano de Ação para prevenção e controle do desmatamento e das queimadas no Cerrado (BRASIL, 2014), o desmatamento no Cerrado tem aumentado de modo intenso em função de suas características propícias à agropecuária e da demanda por carvão vegetal para a indústria siderúrgica, predominantemente nos polos de Minas Gerais e, mais recentemente, de Mato Grosso do Sul. Dentro ou fora da legalidade, os desmatamentos não param, gerando impactos profundos, como a perda da biodiversidade, os danos causados ao solo e aos recursos hídricos, a emissão de gás carbônico, alterações climáticas, extinção da fauna e da flora e, por fim, a desertificação, cujo processo já se encontra desencadeado no sertão nordestino, nos cerrados do Tocantins, na região dos pampas gaúchos, no norte de Mato Grosso e de Minas Gerais (TETILA, 2017). A Carta da Terra da Organização das Nações Unidas (ONU) manifesta que o destino comum nos conclama a buscar um novo começo. Resta saber se a sociedade reagirá e partirá em busca de um novo modelo de desenvolvimento agrícola, com consciência ecológica e baseado na sustentabilidade (BRASIL, 2020). 


\subsection{Queimadas da fauna e flora sul-mato-grossense}

As queimadas têm avançado sobre nichos ecológicos, como formações arbóreas, arbustivas e herbáceas, além de áreas de proteção. Em Mato Grosso do Sul, o número de queimadas vem sendo superado ano após ano. Dados do Programa Queimadas do Instituto Nacional de Pesquisas Espaciais (Inpe) mostram que, seis anos atrás, o estado registrou 655 casos nos sete primeiros meses, mas, em 2017, já acumula 1.916 incêndios rurais no mesmo período. Esse valor é maior que o número de casos de 2016 em 37\%, quando 1.397 focos foram contabilizados pelo Inpe, no Boletim Mensal do Programa de Monitoramento e Risco de Queimadas e Incêndios Florestais de maio de 2017 (INPE, 2017).

O uso do fogo é considerado uma técnica nociva e ultrapassada, pois destrói a biodiversidade local, eliminando várias formas de vida. A temperatura numa queimada pode superar 800 은 centígrados, ocasionando a morte de animais, quando não lesionados ou intoxicados. Não obstante as queimadas estarem enquadradas como crime ambiental (Lei 9.605/98) e também pesquisas demonstrarem que existem técnicas mais avançadas que o fogo para melhorar a produtividade, ainda assim, mais de $90 \%$ dos incêndios florestais são provocados por ação humana, de origem proposital, acidental ou por negligência (INPE, 2017).

O desmatamento quando realizado por meio de queimadas traz prejuízos ainda maiores para o solo e ao meio ambiente. O carvão vegetal resultante das queimadas frequentemente é despejado nos mananciais pelas águas das chuvas, ocasionando intoxicação por monóxido de carbono (CO) de parte da fauna aquática. Embora a queima ou a carbonização da madeira tenha deixado de ser praticada em muitos países, no Brasil ela ainda é bastante comum. O país ocupa o primeiro lugar na produção dessa substância, em razão de o carvão vegetal ser muito utilizado para abastecer diversos setores da economia e a indústria siderúrgica (IBGE, 2015). Um novo relatório da ONU Meio Ambiente (2017) afirma que cerca de 19 milhões de mortes prematuras ocorrem ao ano, em todo o mundo, devido a diversas formas de poluição e pela maneira como as sociedades usam os seus recursos naturais e afetam o meio ambiente para a produção e o consumo (AGÊNCIA BRASIL, 2017).

Por outro lado, o estado de Mato Grosso do Sul alcançou um milhão de hectares de florestas plantadas em 2017, posicionando-se como o segundo maior produtor de eucalipto do país, segundo a Secretaria de Meio Ambiente, Desenvolvimento, Produção e Agricultura Familiar (MATO GROSSO DO SUL, 2017). Apesar dos inúmeros benefícios que as empresas de celulose trouxeram a MS, pouco do carvão vegetal proveniente das florestas plantadas (maciços florestais) vem sendo utilizado pelas usinas siderúrgicas. Grande parte dos plantios de eucalipto e pinos tem sido destinada à produção de papel e celulose (8.293.047 m³), e não de carvão vegetal (156.000 $\mathrm{m}^{3}$ ) (IBGE, 2014). Mesmo com tantos compromissos assumidos pelo fim do desmatamento dos biomas sul-mato-grossenses, as usinas siderúrgicas continuam a receber o carvão vegetal, muitas vezes proveniente de desmatamentos clandestinos e ilegais. Enquanto seguir em frente a venda ilegal de carvão vegetal para as usinas siderúrgicas, o Cerrado continuará perdendo área de sua vegetação original (OLLIVEIRA; MEDEIROS; DIETTRICH, 2018).

\subsection{Assoreamento do Pantanal}

A continuidade do processo de assoreamento atuando diretamente nos cursos de água da bacia pantaneira, juntamente do aumento das precipitações na região, tem aumentado as áreas de inundação no Pantanal (ABDON, 2004). O problema está no desmatamento do arco dos 
planaltos circundantes, ou seja, no Peripantanal. Desde o século passado, essas áreas elevadas vêm perdendo a sua cobertura original. Formações vegetais densas de florestas e cerrados estão sendo substituídas pela expansão de novas áreas agropecuárias, o que vem impactando a planície pantaneira com um dos grandes males ambientais, o assoreamento, como mostra a Figura 2.

Figura 2 - Assoreamento no rio Taquari com suas margens rompidas, município de Corumbá. Coord. geogr. do local $18^{\circ} 25^{\prime} 48^{\prime \prime} \mathrm{S} 54^{\circ} 53^{\prime} 09^{\prime \prime} \mathrm{W}$

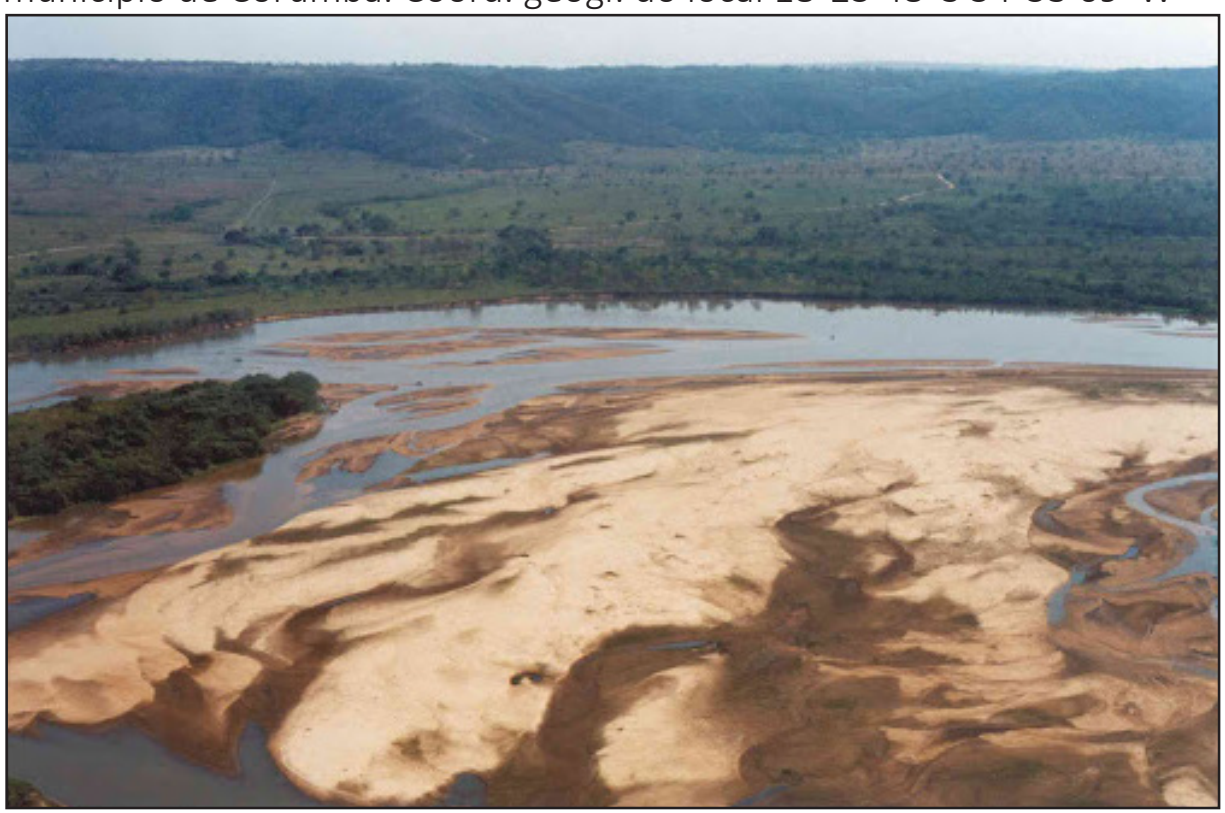

Fonte: INPE (2004). Foto: João Vila.

Oportuno observar que, nas condições originais, parte substantiva das chuvas precipitadas sobre esses planaltos era absorvida e infiltrada no solo pelo seu manto vegetal, resultando, por sua vez, em imensas reservas hídricas nessas partes altas, cujas águas só eram liberadas paulatinamente, mediante miríades de nascentes de água limpa, sobretudo nos períodos de seca. Assim era assegurada a hidrorregulação de toda a bacia pantaneira, fato que perpetuava o vai e vem das águas, isto é, o regime hidrológico das cheias e vazantes de todo o Pantanal. A bacia pantaneira é uma legítima importadora hídrica do arco de planaltos circundantes, onde nasce a quase totalidade dos rios que a abastecem e que the garantem a exuberância da vida presente. Ocorre que esses planaltos ainda continuam vitimados pelo desmatamento. A rigor, o assoreamento vem sendo apontado como um dos maiores problemas da ecologia mundial. No Pantanal, como em toda parte de MS, é o desmatamento que subtrai a profundidade dos rios, lagos, lagoas, baías e corixos, impactando várias formas de vida local e regional (TETILA, 2017).

No bioma pantaneiro, os prejuízos causados pelo assoreamento são bastante visíveis. Já se percebe, por exemplo, quanto o ritmo hidrológico, que condiciona o ritmo biológico, vem sendo quebrado. Áreas que ficavam alagadas somente em períodos definidos (secas) agora ficam o ano todo submersas. Na região do Taquari, o rio, perdendo o próprio leito, passou a inundar permanentemente. Uma área em torno de 500 mil hectares encontra-se permanentemente submersa, representando imensos prejuízos para a pecuária e a pesca dessa região (EMBRAPA, 2005). Além disso, dezenas de propriedades rurais já se acham inutilizadas em face do binômio assoreamento/alagamento. 
Oportuno lembrar que no período das chuvas descia rio abaixo a matéria orgânica produzida pelo manto vegetal que recobria os planaltos circundantes, e não a areia. Descia o húmus, fertilizante natural, levado pelas enchentes e depositado sobre os prados, beneficiando cerca de dois terços da grande planície. Atualmente, o Pantanal, considerado Reserva da Biosfera e Patrimônio Natural da Humanidade pela Unesco, está vulnerável com o assoreamento de mananciais no estado, impactando negativamente a navegabilidade das embarcações, a atividade da pesca e o alagamento do habitat das populações ribeirinhas (BRASIL, 2014). O problema do desmatamento continua rondando-Ihe os planaltos circundantes (TETILA, 2017).

Diante desse cenário, resta-nos saber o que acontecerá quando o manto vegetal remanescente nessas áreas em declive tiver desaparecido, ou quando toda a capa arenosa dessas mesmas áreas tiver sido transportada para o interior da bacia pantaneira. Em contrapartida, alguns proprietários vêm investindo, conscientemente, em novas tecnologias de manejo e conservação do solo e da água, de manejo integrado de pragas e doenças, plantio direto, rotação e diversificação de culturas, manutenção de áreas de refúgio para os inimigos naturais de pragas, entre outras ações de bases sustentáveis (CONAB, 2019). A União, por meio da Agência Nacional de Águas, vem liberando 5 milhões de reais, desde 2007, para a recuperação de microbacias e implantação de viveiros de mudas para o plantio no entorno dos mananciais oriundos dos planaltos (TETILA, 2017). Há ainda uma preocupação constante de universidades, centros de pesquisa e projetos de extensão em trabalhar aspectos e características da hidrodinâmica regional. São perspectivas positivas, em face da dimensão já tomada pelo assoreamento da bacia pantaneira.

\subsection{Corredores ecológicos como alternativa para a fragmentação ecológica de MS}

Com a expansão da fronteira agrícola ao longo do tempo, os biomas de Mato Grosso do Sul, como as matas tropicais, os cerrados e outras formações vegetais, estão sendo progressivamente reduzidos a fragmentos de habitats em face do desmatamento, formando pequenas ilhas de biodiversidade. Esses fragmentos de habitats são isolados uns dos outros e circundados por áreas monocultivadas, cujos impactos marcantes e negativos têm se refletido sobre a fauna e a flora remanescentes dessas áreas. Esse processo, conhecido como fragmentação de habitats, é considerado uma das maiores ameaças à biodiversidade (SEOANE et al., 2010).

Do ponto de vista geográfico, plantas e animais silvestres da rica biodiversidade sul-matogrossense vêm passando pelo problema do confinamento espacial, tamanha é a redução e o isolamento de seus habitats, cuja preservação vem se tornando cada vez mais difícil. A distância entre esses fragmentos dificulta a conectividade entre a fauna e a flora e, consequentemente, a propagação do pólen, das sementes, bem como o fluxo gênico entre as espécies. Por conta da distância dos fragmentos entre si, assim como do isolamento imposto à fauna, também surge o problema da consanguinidade, isto é, o acasalamento entre indivíduos que apresentam grau de parentesco, o que fragiliza a saúde e acelera o processo de extinção desses animais (TETILA, 2017).

Conservar a biodiversidade em áreas intensamente cultivadas, como já acontece em boa parte do território sul-mato-grossense, tem sido um grande desafio para o desenvolvimento sustentável. Todavia não há como manter a biodiversidade, em espaços intensamente ocupados pela agropecuária, sem que ocorra a interligação entre os fragmentos florestais. Felizmente, isso vem se tornando possível por meio dos chamados "corredores ecológicos". Corredores mundialmente considerados como uma estratégia moderna capaz de melhorar a biodiversidade 
local e regional, bem como a biosfera como um todo, por estabelecer a imprescindível rede de interações entre os fragmentos e suas respectivas espécies (TETILA, 2017).

Além disso, se bem preservados e conectados, podem prestar bons serviços ecossistêmicos às propriedades: ajudar no controle de doenças, plantas infestantes e pragas, na retenção de água no solo, no fornecimento de sementes para reflorestamentos, na melhoria do microclima, na polinização de lavouras e pomares, e ainda dar suporte à ciência, pesquisa e inovação tecnológica. Apesar de tudo, a importância da biodiversidade é algo que vem sendo crescentemente percebida. De modo geral, há uma preocupação mundial quanto à preservação dos processos naturais que dão suporte à vida, especialmente quando se trata do amplo espectro de ecossistemas que tão bem caracteriza a biodiversidade sul-mato-grossense (TETILA, 2017).

\subsection{Sementes crioulas na preservação da biodiversidade}

As sementes crioulas são aquelas sementes naturais que não foram geneticamente modificadas, ou seja, sementes que foram produzidas por famílias de agricultores desde os seus ancestrais e melhoradas pelo processo de seleção natural darwiniana. A valorização das sementes crioulas pela agricultura familiar amplia a biodiversidade local, pois nelas se resguarda o equilíbrio ecossistêmico da biota à qual pertencem, preserva a riqueza genética, garante a sustentabilidade com base na agroecologia, a produção de alimentos saudáveis, e, acima de tudo, contribui para a preservação das sementes crioulas, pois a Organização das Nações Unidas para a Alimentação e a Agricultura (FAO) estima que, no último século, cerca de $75 \%$ de toda a diversidade genética de cultivares do planeta tenha desaparecido (TETILA, 2017).

Muitos estados brasileiros têm realizado feiras de sementes crioulas e produtos agroecológicos, reunindo milhares de interessados. Em Mato Grosso do Sul, a Feira de Sementes Crioulas organizada pela Comissão Pastoral da Terra é realizada no município de Juti e reúne agricultores familiares e comunidades tradicionais de todo o país. No Rio Grande do Sul, em seis edições da Feira Canguçu, estima-se que mais 100 mil pessoas já participaram do evento. $\mathrm{Na}$ última edição da feira, em 2013, aproximadamente 3,6 mil kg de sementes crioulas foram comercializadas diretamente pelo sistema de troca entre os agricultores e 30 mil kg de sementes crioulas pela Cooperativa União para a Secretaria de Desenvolvimento Rural do Município de Canguçu, beneficiando mais de 13 mil famílias (AGUIAR, 2017).

Essas feiras possibilitam ampliar a troca de sementes crioulas e experiências entre os agricultores de diversas regiões, bem como o intercâmbio e as discussões que promovem a difusão de práticas de uso sustentável dos recursos naturais por meio de oficinas temáticas realizadas. Nas oficinas, destaca-se a defesa desse patrimônio imprescindível para a humanidade: as sementes, significando o resgate de centenas de variedades de espécies, assim como a necessidade de um modelo agrícola sustentável, que seja capaz de reconstruir a base genética e devolver a soberania alimentar dos povos e a sua cultura regional.

\subsection{Transição do modelo agroquímico para o agroecológico}

Estima-se que, em todo o mundo, cerca de três milhões de casos de intoxicação por pesticidas ocorrem todos os anos, resultando em 250.000 mortes, de acordo com a Word Health Organization (WHO, 2004). As intoxicações ocasionadas por pesticidas podem ser agudas, suscitando sintomas logo após o contato, ou crônicas, quando o indivíduo é exposto a pequenas 
quantidades por longos períodos, podendo ocasionar: redução do sistema imunológico e nervoso central, desregulação endócrina, infertilidade, impotência, aborto, malformações e câncer (INSTITUTO NACIONAL DO CÂNCER [INCA], 2015). A procura por produtos limpos vem ganhando importância a ponto de eles serem recomendados, reiteradamente, pela Organização Mundial de Saúde (OMS), já que reduzem o índice de doenças decorrentes do padrão convencional de alimentação (WHO, 2004).

Há de se reconhecer a importância dessa transição que vem sendo proposta mundialmente, dada a crescente demanda por produtos limpos, orgânicos e saudáveis. Nos últimos três anos, a produção agroecológica brasileira mais do que dobrou, passando de 6.700 mil unidades (2013) para aproximadamente 15.700 (2016), mas a área plantada (750 mil hectares) ainda é considerada pequena em relação a outros países, e os esforços para desenvolver uma abordagem sustentável permanecem insuficientes, segundo o Ministério do Desenvolvimento da Agricultura (BRASIL, 2017). Isso sinaliza para uma maior atenção às leis da vida, uma vez que os pesticidas podem contaminar os mananciais, fauna, flora e, sobretudo, os alimentos.

A agroecologia, com sua base tecnológica natural que prioriza a qualidade dos alimentos, vem demonstrando o quanto é possível extrair da terra alimentos limpos e saudáveis, capazes de prevenir, bloquear e até reverter doenças (quimiopreventivos), garantindo, dessa forma, a segurança alimentar. Livres de pesticidas e de adubos químicos, a produção agroecológica tem nutrientes mais concentrados e bem mais deleitosos em aroma e sabor, além de serem mais ricos em vitaminas, proteínas e sais minerais. Isso leva os consumidores a comerem menos e a se nutrirem mais, minimizando custos com medicamentos e a recuperação ambiental. Por outro lado, por meio da agricultura convencional, as pessoas acabam comendo mais para saciar a fome, pois os pesticidas eliminam boa parte dos micro-organismos do solo, reduzindo os teores de vitaminas e sais minerais (TETILA, 2017).

Sem embargo do respaldo econômico importante que o setor agropecuário representa para a economia de MS, centrado na produção extensiva de commodities e manejo de pesticidas, não há como desvincular os enormes passivos ambientais e os efeitos nocivos à saúde humana. Com base em pesquisa realizada pela Agência Internacional de Pesquisa em Câncer, o Inca tem recomendado "o estabelecimento de ações que visem à redução progressiva e sustentada do uso de pesticidas, conforme previsto no Programa Nacional para Redução do Uso de Agrotóxicos-Pronara" (INCA, 2015). O instituto defende, ainda, a substituição progressiva desse modelo dominante pela produção de base agroecológica, em acordo com a Política Nacional de Agroecologia e Produção Orgânica (INCA, 2016).

Indubitavelmente, a aplicação de pesticidas precisa ser reduzida para o bem da saúde pública e de toda a base biológica existente. Assim, pela agroecologia está aberto o caminho tanto para produção de alimentos ricos e saudáveis quanto para a geração de mais empregos e renda no campo, ampliação do patrimônio genético, diversidade biológica e longevidade. Por intermédio dessa ciência está presente o novo paradigma para construção de um desenvolvimento agrícola sustentável, centrado na vida biocêntrica e no respeito à natureza. Aos produtores convencionais, a agroecologia oferece a oportunidade de uma alternativa ecologicamente correta, convidandoIhes a fazer parte dessa transição.

Felizmente, o nosso país já despertou para esse crescente ciclo de renovação, o qual haverá de efetivar a conquista de um mercado que vem sendo aberto mundialmente, com amplas possibilidades de o Brasil tornar-se referência mundial na produção agroecológica, haja vista as 
dimensões continentais de seu território e a diversidade de climas e solos propícios. Em Mato Grosso do Sul, por exemplo, algumas iniciativas agroecológicas bem-sucedidas já foram realizadas para a produção de alimentos, como a abertura de novas empresas de revenda de produtos de controle biológico, a criação da Secretaria Municipal de Agricultura Familiar e Economia Solidária no município de Dourados e a implantação do Curso Superior de Tecnologia em Agroecologia no município de Glória de Dourados, pela Universidade Estadual de Mato Grosso do Sul (Uems) (TETILA, 2017).

\subsection{Tecnologias de agricultura de precisão para produção agropecuária}

Durante as próximas duas décadas, uma onda tecnológica deverá revolucionar a eficiência das propriedades agrícolas em todo o mundo, mas pode não ser o bastante. Estima-se que até 2050 a população humana será de quase 10 bilhões (UNITED NATIONS, 2017), o que significa que será preciso aumentar substancialmente a quantidade de alimentos produzidos atualmente. Inovações tecnológicas como veículos aéreos não tripulados (Vants) têm revolucionado a produção de alimentos no campo. Na agricultura de precisão, o uso de Vants tem ajudado no mapeamento/ monitoramento do cultivo/colheita de propriedades agrícolas de todos os tamanhos, o que tem contribuído com o aumento da produção de alimentos e a redução dos custos de produção. Vants equipados com câmeras de alta resolução espacial são capazes de sobrevoar uma plantação a poucos metros de distância e capturar imagens em alta definição (TETILA, 2019).

Os Vants também podem ser programados para executar operações de plano de voo automático, possibilitando realizar inspeções regulares em grandes áreas e operações com maior periodicidade no acompanhamento de toda a safra. Inspeções regulares com os Vants são imunes à presença de nuvens, o que pode variar a intensidade e as características espectrais dos alvos. O trabalho realizado com o levantamento aéreo viabiliza a construção de um banco de dados da propriedade (p. ex., histórico de produção, definição de zonas de manejo, monitoramento de áreas verdes, manutenção de recursos hídricos, aplicação de insumos em taxa variável etc.) que auxilia na execução de estratégias futuras. Desse modo, o uso de Vants em campos de cultivo tem sido considerado um importante instrumento para agricultores e especialistas tomarem melhores decisões de manejo (TETILA, 2019).

As demandas atuais de eficiência econômica e ambiental da agricultura moderna indicam a necessidade de incorporar novos sistemas inteligentes de automação e manejo, capazes de processar os dados coletados em campo para o monitoramento preciso das lavouras. 0 monitoramento viabiliza a aplicação de insumos em taxas variadas, orientando a gestão dos sistemas agrícolas, em harmonia com as questões ambientais. Além disso, possibilita aumentar a produção de alimentos no campo para atender o crescimento da população mundial. Esperase que a adoção desses sistemas inteligentes se torne mais comum, eficiente e sustentável do que os sistemas atuais usados em gerenciamento de lavouras (TETILA, 2019).

\section{ABORDAGEM PROPOSTA}

Esta seção apresenta uma proposta baseada em alternativas ecologicamente corretas e iniciativas de preservação, rumo à construção da sustentabilidade ambiental e do bem-estar social do estado de Mato Grosso do Sul.

Com o avanço sistemático da atividade agropecuária, os cerrados e outras formações 
vegetais vêm passando por um forte processo de degradação ambiental. Embora o estado de MS ostente dois níveis morfológicos bem distintos, planalto e planície, o que acontece no arco dos planaltos circundantes acaba impactando a planície, tal a relação de dependência existente entre esses dois níveis - entendimento fundamental para o incremento de ações e projetos sustentáveis, prioritariamente, sobre os planaltos. Nesses planaltos é que se encontram as cabeceiras dos principais rios do estado e de onde vertiam as fontes que abastecem o sistema hidrológico de toda a bacia sul-mato-grossense. Por se tratar de planaltos sedimentares, são extremamente suscetíveis ao processo erosivo; e, com a rápida supressão da cobertura florestal verificada, principalmente no bioma Cerrado, está se suprimindo de forma notável esse bioma, tido como o pilar de sustentação da planície pantaneira.

O Cerrado, com suas raízes profundas, exerce função ecológica da maior importância, qual seja, fixar e garantir a estabilidade dos solos dos planaltos. Nesse bioma, raízes pivotantes e ramificadas podem alcançar de 10 a 15 metros de profundidade, bem diferente da maioria das florestas brasileiras, cujas raízes dificilmente chegam a essa profundidade. A trama das raízes do Cerrado, além da função ecológica de estabilizar o solo evitando a sua perda pela erosão, exerce importante função ecológica de hidrorregulação durante todo o ano. Com o desmatamento progressivo, sobretudo do Cerrado, uma das consequências tem sido a redução da oferta hídrica durante as secas e o seu aumento durante o período chuvoso, com profundos reflexos na biodiversidade.

O Cerrado também perdeu, em grande parte, a sua condição de maciço florestal. Desfigurado, aparece em fragmentos próximos de $24 \%$ e, uma vez eliminados, muito pouco poderá ser feito para livrar a planície pantaneira de converter-se num imenso areal. Na falta desse manto protetor que garante a estabilidade do solo dos planaltos, o resultado tem sido o desencadeamento de um processo erosivo (laminar, em sulcos e até em voçorocas) sem precedentes, com o arraste de milhões de toneladas de terra (descarga sedimentar), levadas de roldão até o destino final, que são os leitos dos rios e demais mananciais, com o deletério fenômeno do assoreamento.

O assoreamento, com efeito, tem sido apontado como grave problema de degradação ambiental. Ao reduzir a profundidade dos rios e dos mananciais, ele acaba aumentando a amplitude das enchentes, inundando áreas que antes não eram atingidas pelas cheias, com perda da vegetação subaquática e grandes prejuízos à biodiversidade local; além da precarização que vem causando à navegabilidade, cujas embarcações, não raro, deparam-se com encalhes sobre bancos de areia, cada vez mais presentes nos rios pantaneiros, inclusive, em sua principal artéria, o rio Paraguai.

Nas encostas dos planaltos, a extração do carvão vegetal é algo que vem resultando na queima continuada do que ainda resta de fragmentos vegetais (Cerrado e matas ciliares), procedimento que vem transformando a biodiversidade remanescente em cinzas e fuligens, formando um composto que, nos períodos chuvosos, chega aos rios da planície por escoamento superficial. É a temível decoada, que também subtrai o oxigênio da água, podendo causar a mortandade de toneladas de peixes, tal como tem sido historicamente registrado. Do ponto de vista climatológico, pancadas de chuva (impactos pluviais concentrados), comuns durante o verão, eram amortecidas pelo manto protetor da vegetação. Atualmente, com esse manto reduzido em $76 \%$, acarretou-se o processo erosivo sobre esses planaltos, para agravo ainda maior do assoreamento da planície.

Enfim, para assegurar a preservação e perpetuação da biodiversidade local, aponta-se, como 
centro do problema o bioma Cerrado, bem como as matas ciliares, mencionando as seguintes medidas e conjugação de esforços na implementação de ações de restaúração e preservação ambientais:

1) Identificação de espécies nativas de MS;

2) Laboratório de sementes;

3) Viveiro de mudas nativas;

4) Recuperação de florestas nativas com a formação de corredores ecológicos;

5) Dragagem de rios e mananciais nos cursos de água;

6) Transição do modelo agroquímico para o agroecológico;

7) Eliminação de toda atividade carvoeira proveniente de matas nativas de MS;

8) Incentivo à adoção da agricultura de precisão na produção agropecuária;

9) Revisão da legislação no que se refere às especificidades geoecológicas.

Uma das dificuldades para a recuperação ambiental é conhecer as espécies nativas indicadas para cada bioma ou fitofisionomia. Em Embrapa (2012a), estão disponíveis informações sobre as espécies dos biomas Cerrado, Mata Atlântica e Pantanal, recomendadas para a recomposição de Áreas de Preservação Permanente, de Reserva Legal e de Uso Restrito (veja passo (a) da Figura 3). Esse levantamento foi realizado pela Empresa Brasileira de Pesquisa Agropecuária (Embrapa), em parceria com Ministério do Meio Ambiente, por meio da Secretaria de Extrativismo e Desenvolvimento Rural Sustentável e do Serviço Florestal Brasileiro.

Figura 3 - Abordagem proposta para o modelo de desenvolvimento agrícola do estado de Mato Grosso do Sul

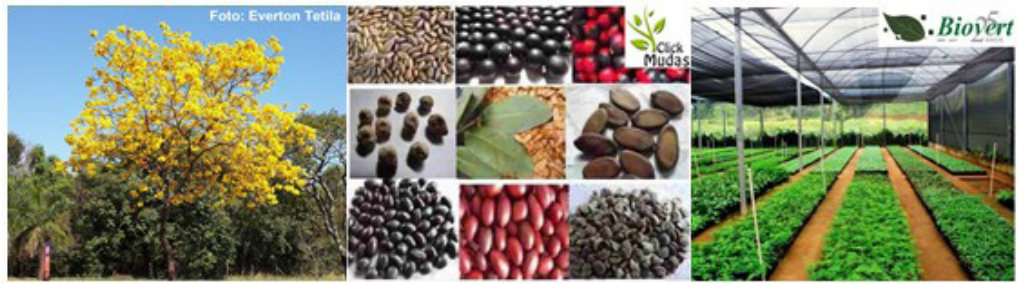

(a)

(b)

(c)

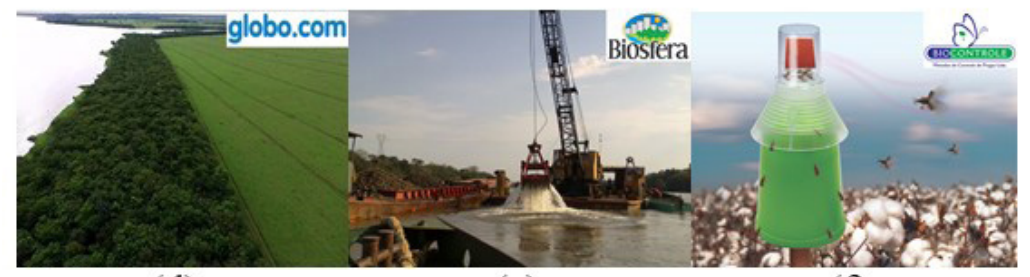

(d)

(e)

(f)

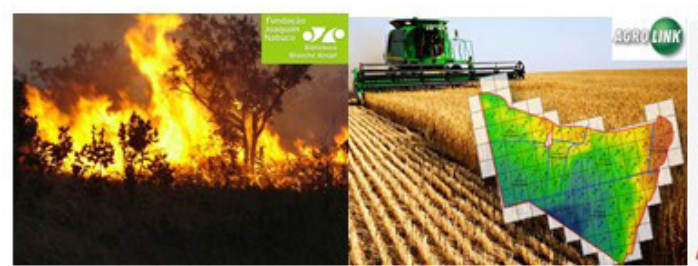

(g) (h)

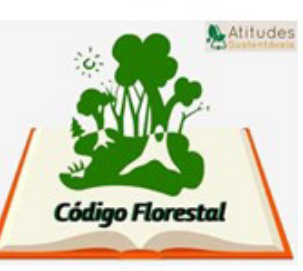

(i)

Fonte: Compilação do autor. Montagem a partir de imagens coletadas nos sites: Click Mudas, Biovert, Globo, Biosfera, Biocontrole, Fundação Joaquim Nabuco, Agrolink e Atitudes Sustentáveis. 
A identificação de espécies nativas de MS, bem como o planejamento da recuperação ambiental das áreas degradadas, deve primar-se pela implantação de laboratórios de sementes (veja passo (b) da Figura 3) e viveiros de mudas nativas (veja passo (c) da Figura 3) para o reflorestamento das áreas desmatadas do Cerrado e das matas ciliares, no nível dos planaltos. Em Embrapa (2012b, 2012c), encontra-se disponível para consulta uma lista contendo diversos produtores de sementes e viveiros de espécies florestais.

Dada a sua importância na articulação de animais e plantas entre os fragmentos florestais remanescentes, no nível dos planaltos, deve-se proceder o estudo de viabilidade para a implantação de corredores ecológicos (veja passo (d) da Figura 3), bem como proceder a ampliação das áreas florestais de proteção integral e de uso sustentável (público-privadas) na região dos planaltos, para que os sistemas naturais dessa região voltem a recuperar a sua biocapacidade (capacidade biológica regenerativa da natureza) e a prestar os serviços ambientais (funções ecológicas), como segurança pedológica (estabilidade dos solos), segurança hídrica (hidrorregulação), fertilização das pastagens (liberação do húmus em vez da areia, durante as enchentes), além do retorno da atividade pesqueira, a navegabilidade dos rios, a disseminação de sementes e a reprodução animal.

Em face da afirmação da Embrapa de que o Brasil tem enormes áreas já degradadas por onde pode expandir a sua produção, sem precisar converter nenhuma nova área; e considerando que, em Mato Grosso do Sul, algumas estimativas indicam que pelo menos $50 \%$ das áreas ocupadas com pastagens cultivadas nessa região apresentam algum grau de degradação (EMBRAPA, 2004), é preciso que esforços sejam envidados para banir qualquer tentativa de novos desmatamentos na região dos planaltos, para a garantia de um futuro sustentável, assim como é necessário:

- Indicar a premente necessidade de ações de natureza preventiva e corretiva, por meio de planejamento técnico e gestão participativa, a operação de dragagem para a recuperação e conservação dos leitos dos rios e mananciais nos cursos de água, em combate ao grave problema de degradação ambiental provocado pelo assoreamento (veja passo (e) da Figura 3).

- Implantar amplo programa de restauro ambiental nas áreas já degradadas, especialmente na região dos planaltos circundantes, mediante estabelecimento de boas práticas voltadas à conversão do modelo agroquímico para o modelo agroecológico de produção rural (veja passo (f) da Figura 3), num processo que envolva os diferentes setores da sociedade civil que possam contribuir técnica e cientificamente nesse mister. Também, implantar laboratórios de análise de resíduos químicos a fim de constatar os efeitos deletérios ao meio ambiente e à saúde humana, bem como coibir o uso de pesticidas proibidos que são contrabandeados principalmente pelo Paraguai; e ampliar o quadro efetivo para a demanda tanto laboratorial como de fiscalização.

- Analisar todas possibilidades para a proibição total da atividade carvoeira (produção, transporte e uso de carvão vegetal) proveniente de matas nativas do estado de Mato Grosso do Sul (veja passo (g) da Figura 3), haja vista a recente projeção do desmatamento no bioma Cerrado e matas ciliares no nível dos planaltos, com impactos profundos à biodiversidade.

- Incentivar, por meio de parcerias público-privadas (PPPs), a adoção de novas tecnologias aliadas à agricultura de precisão, que sejam capazes de: (1) impulsionar a produção agropecuária, reduzindo a quantidade necessária de pesticidas nos campos de cultivo; (2) contribuir com o desenvolvimento social, gerando novas vagas de trabalhos de mão de obra especializada; (3) reduzir o impacto ambiental, decorrente do uso excessivo de pesticidas; e (4) contribuir com a questão da segurança alimentar e bem-estar social, por meio de uma abordagem baseada em alternativas ecologicamente corretas (veja passo (h) da Figura 3). 
- Revisar a legislação no que se refere às especificidades geoecológicas (veja passo (i) da Figura 3) com foco no desenvolvimento sustentável no nível dos planaltos circundantes, tendo como meta eliminar os passivos ambientais já acumulados na planície; e ensejar monitoramentos e fiscalizações com multas, quando necessário, além da aplicação responsável de legislação ambiental já existente, com ênfase na região dos planaltos.

\section{CONCLUSÃO}

Este artigo apresentou uma discussão sobre o atual modelo de desenvolvimento agrícola do estado de Mato Grosso do Sul e as principais causas das transformações ambientais que prejudicam o meio ambiente, gerando várias implicações sobre os biomas já fragilizados. Uma abordagem proposta, baseada em alternativas ecologicamente corretas e iniciativas de preservação, foi apresentada para o desenvolvimento sustentável do estado. Essa proposta foi concebida a partir de nove medidas e conjugação de esforços na implementação de ações de restauração e preservação ambientais, apontando como centro das preocupações o bioma Cerrado, bem como as matas ciliares, áreas essenciais para a preservação e perpetuação da biodiversidade local. Destacam-se, ainda, os riscos do uso crescente de pesticidas e seus efeitos nocivos ao meio ambiente e à saúde humana, devido à contaminação da fauna e da flora, do solo, do ar e da água, os quais são manifestados por organismos nacionais e internacionais renomados sobre o assunto.

Pelo exposto, reitera-se a importância de todo o empenho na execução das medidas preventivas e regenerativas dos biomas, com foco na sustentabilidade do arco de planaltos, além da necessidade de políticas públicas que incentivem a transição do modelo agroquímico para o modelo agroecológico a bem da saúde ambiental, afirmando-lhe a importância da restauração e preservação da natureza e a garantia de um futuro sustentável.

\section{AGRADECIMENTOS}

Os autores prestam os seus agradecimentos ao Centro Nacional de Desenvolvimento Científico e Tecnológico (CNPq), à Coordenação de Aperfeiçoamento de Pessoal de Nível Superior (CAPES) pela bolsa de Doutorado concedida a um dos autores e à Fundação de Apoio ao Desenvolvimento do Ensino, Ciência e Tecnologia do estado de Mato Grosso do Sul (FUNDECT) pelo financiamento do projeto que originou este trabalho.

\section{REFERÊNCIAS}

ABDON, M. M. Os impactos ambientais no meio físico: erosão e assoreamento na Bacia Hidrográfica do Rio Taquari, MS, em decorrência da pecuária. 2004. Tese (Doutorado em Ciências da Engenharia Ambiental) - Escola de Engenharia de São Carlos, Universidade de São Paulo, São Carlos, SP, 2004.

AGÊNCIA BRASIL. Novo relatório da ONU define caminhos para um planeta livre de poluição. ONU News, Genebra, Suíça, 2017. Disponível em: http://agenciabrasil.ebc.com.br/internacional/noticia/2017-10/ novo-relatorio-da-onu-define-caminhos-para-um-planeta-livre-de. Acesso em: 15 jul. 2020.

AGUIAR, R. Feira de Sementes Crioulas é lançada no Espaço Casa da Emater. Assessoria de Imprensa da Emater/RS-Ascar na Expoagro. 22 mar. 2017. Disponível em: http://olajornal.com.br/feira-de-sementescrioulas-e-lancada-no-espaco-casa-da-emater\%EF\%BB\%BF/. Acesso em: 15 jul. 2020. 
BERNARDI, A. C. C.; NAIME, J. M.; RESENDE, A. V.; BASSOI, L. H. V.; INAMASU, R. Y. (Ed.). Agricultura de precisão: resultados de um novo olhar. Brasília, DF: Embrapa Instrumentação (CNPDIA), 2014. 596 p. Disponível em: http://ainfo.cnptia.embrapa.br/digital/bitstream/item/113993/1/Agricultura-deprecisao-2014.pdf. Acesso em: 15 jul. 2020.

BETTIOL, W. et al. Produtos comerciais à base de agentes de biocontrole de doenças de plantas. Jaguariúna, SP: Embrapa Meio Ambiente, 2012. Documentos 88, 156 p.

BRASIL. Ministério da Agricultura, Pecuária e Abastecimento (MAPA). Portaria n. 852 - Art. 10 Criar a Comissão Brasileira de Agricultura de Precisão - CBAP. Diário Oficial [da] República Federativa do Brasil, Brasília, DF, 21 set. 2012.

BRASIL. Ministério do Desenvolvimento Agrário (MDA). Mais orgânicos na mesa do brasileiro em 2017. Maria Júlia Lledó, 18 jan. 2017. Disponível em: http://www.fao.org/family-farming/detail/en/c/463455/. Acesso em: 15 jul. 2020.

BRASIL. Ministério do Meio Ambiente (MMA). Carta da terra. 2020. Disponível em: http://www.mma.gov. br/responsabilidade-socioambiental/agenda-21/carta-da-terra. Acesso em: 15 jul. 2020.

BRASIL. Ministério do Meio Ambiente (MMA). Plano de Ação para prevenção e controle do desmatamento e das queimadas no Cerrado - PPCerrado - 2a fase (2014-2015). Brasília: MMA, 2014. Disponível em: http://www.mma.gov.br/estruturas/201/_arquivos/ppcerrado_201.pdf. Acesso em: 15 jul. 2020.

COMPANHIA NACIONAL DE ABASTECIMENTO (CONAB). Acompanhamento da Safra Brasileira de Grãos, Brasília, DF, v. 6, n. 9, p. 1-113, jun. 2019. (Safra 2018/19 - Nono levantamento). Disponível em: https:// www.conab.gov.br/component/k2/item/download/26760_37779459c5d79f63129c8c8c4d634103. Acesso em: 15 jul. 2020.

COMPANHIA NACIONAL DE ABASTECIMENTO (CONAB). Evolução dos custos de produção de soja no Brasil. Compêndio de Estudos Conab, Brasília, DF, v. 2, 2016. Disponível em: https://www.conab.gov.br/ institucional/publicacoes/compendio-de-estudos-da-conab/item/2890-compendio-de-estudos-da-conabv-2-evolucao-dos-custos-de-producao-de-soja-no-brasil. Acesso em: 15 jul. 2020.

CORREA-FERREIRA, B. S.; ROGGIA, S.; SEIXAS, C. D. S. Armadilha para captura de percevejos em soja. Embrapa Soja, 2016. Disponível em: https://www.embrapa.br/soja/busca-de-solucoes-tecnologicas/-/ produto-servico/6040/armadilha-para-captura-de-percevejos-em-soja. Acesso em: 15 jul. 2020.

COSTA, C. O.; QUEIROZ, A. P.; TAGUTI, E. A.; GRANDE, M. L. M.; BUENO, A. F. Preferência hospedeira do parasitoide Telenomus podisi Ashmead (Hymenoptera: Scelionidae) entre ovos de Dichelops melacanthus, Euschistus heros e Podisus nigrispinus (Hemiptera: Pentatomidae). Londrina, PR: Embrapa Soja, 2017.

EMPRESA BRASILEIRA DE PESQUISA AGROPECUÁRIA (EMBRAPA). Degradação de Pastagens, Matéria Orgânica do Solo e a Recuperação do Potencial Produtivo em Sistemas de Baixo "Input" Tecnológico na Região dos Cerrados. Embrapa Agrobiologia (CNPAB), Circular Técnica 9, dez. 2004. Disponível em: https://www.embrapa.br/agrobiologia/busca-de-publicacoes/-/publicacao/627822/degradacao-depastagens-materia-organica-do-solo-e-a-recuperacao-do-potencial-produtivo-em-sistemas-de-baixoinput-tecnologico-na-regiao-dos-cerrados. Acesso em: 15 jul. 2020.

EMPRESA BRASILEIRA DE PESQUISA AGROPECUÁRIA (EMBRAPA). Dia de Campo na TV apresenta estudos ambientais do Rio Taquari. Brasília, DF, 2005. Disponível em: https://www.embrapa.br/busca-de-noticias/-/ noticia/17984684/dia-de-campo-na-tv-apresenta-estudos-ambientais-do-rio-taquari. Acesso em: 15 jul. 2020. 
EMPRESA BRASILEIRA DE PESQUISA AGROPECUÁRIA (EMBRAPA). Espécies vegetais para recuperação. Brasília, DF, 2012a. Disponível em: https://www.embrapa.br/codigo-florestal/especies. Acesso em: 15 jul. 2020.

EMPRESA BRASILEIRA DE PESQUISA AGROPECUÁRIA (EMBRAPA). Produtores de sementes de espécies florestais. Brasília, DF, 2012b. Disponível em: https://www.embrapa.br/codigo-florestal/produtores-desementes. Acesso em: 15 jul. 2020.

EMPRESA BRASILEIRA DE PESQUISA AGROPECUÁRIA (EMBRAPA). Viveiros de espécies florestais. Brasília, DF, 2012c. Disponível em: https://www.embrapa.br/codigo-florestal/viveiros-de-especies-florestais. Acesso em: 15 jul. 2020.

FOOD AND AGRICULTURE ORGANIZATION OF THE UNITED NATIONS (FAO). Global forest resources assessment 2015. How are the world's forests changing? Second edition. Rome: FAO, 2016. Disponível em: http://www.fao.org/3/a-i4793e.pdf. Acesso em: 15 jul. 2020.

HECK, D. W.; DORIGHELLO, D. V.; FORNER, C.; BETTIOL, W. Biocontrole de mofo branco em soja com Bacillus spp. In: CONGRESSO BRASILEIRO DE FITOPATOLOGIA, 47.; SIMPÓSIO BRASILEIRO DO MOFO BRANCO, 1., 2014, Londrina. Anais [...]. Londrina, PR: Sociedade Brasileira de Fitopatologia, 2014.

INSTITUTO BRASILEIRO DE GEOGRAFIA E ESTATÍSTICA. Produção da extração vegetal e silvicultura. Rio de Janeiro: IBGE, 2015. v. 30. Disponível em: http://biblioteca.ibge.gov.br/visualizacao/periodicos/74/ pevs_2015_v30.pdf. Acesso em: 15 jul. 2020.

INSTITUTO BRASILEIRO DE GEOGRAFIA E ESTATÍ́STICA. Produção da extração vegetal e da silvicultura. Rio de Janeiro: IBGE, 2014. v. 29, p. 1-56. Disponível em: https://biblioteca.ibge.gov.br/visualizacao/ periodicos/74/pevs_2014_v29.pdf. Acesso em: 15 jul. 2020.

INSTITUTO NACIONAL DE PESQUISAS ESPACIAIS. Boletim Mensal do Programa de Monitoramento e Risco de Queimadas e Incêndios Florestais, São José dos Campos, SP, v. 2, n. 5, maio 2017. Disponível em: http:// queimadas.dgi.inpe.br/queimadas/portal/outros-produtos/infoqueima/2017_05_infoqueima.pdf. Acesso em: 15 jul. 2020.

INSTITUTO NACIONAL DE PESQUISAS ESPACIAIS. Assoreamento no rio Taquari. Areias Quartzosas Hidromórficas distróficas (HAQd2) em área de planície fluvial (Apf). Bacia do rio Taquari na planície, município de Corumbá. Foto de João Vila, em 12 set. 2002.Disponível em: http://mtc-m12.sid.inpe.br/ col/sid.inpe.br/sergio/2004/06.14.16.12/doc/paginas/bbt/assoreamento/-J_120902_8.html. Acesso em: 15 jul. 2020.

INSTITUTO NACIONAL DO CÂNCER. Posicionamento do INCA acerca dos agrotóxicos. Brasília-DF: INCA, 2015. Disponível em: https://www.inca.gov.br/sites/ufu.sti.inca.local/files//media/document// posicionamento-do-inca-sobre-os-agrotoxicos-06-abr-15.pdf. Acesso em: 23 abr. 2018.

INSTITUTO NACIONAL DO CÂNCER. Posicionamento do Instituto Nacional de Câncer José Alencar Gomes da Silva acerca dos agrotóxicos. Brasília-DF: INCA, 2016. Disponível em: https://www.inca.gov.br/sites/ ufu.sti.inca.local/files//media/document//posicionamento-do-inca-sobre-os-agrotoxicos-06-abr-15.pdf. Acesso em: 15 jul. 2020.

MATO GROSSO DO SUL. Secretaria de Meio Ambiente, Desenvolvimento, Produção e Agricultura Familiar (SEMAGRO). Mato Grosso do Sul alcança 1 milhão de hectares de florestas e se destaca como referência no setor. 5 set. 2017. Disponível em: http://www.semagro.ms.gov.br/mato-grosso-do-sul-alcanca-1-milhaode-hectares-de-florestas-e-se-destaca-como-referencia-no-setor/. Acesso em: 15 jul. 2020. 
OLLIVEIRA, A. K. M.; MEDEIROS, C. B.; DIETTRICH, L. C. Atividades antrópicas e a efetividade da atuação do Ministério Público do estado de Mato Grosso do Sul em propriedades rurais. Revista Gestão e Sustentabilidade Ambiental, Florianópolis, v. 7, n. 2, p. 192-205, abr./jun. 2018. DOI: http://dx.doi. org/10.19177/rgsa.v7e22018192-205

PEDIGO, L. P. Entomology and pest management. 4. ed. Upper Saddle River, Nova Jersey, EUA: Prentice Hall, 2001. 742 p.

SEOANE, C. E. S.; DIAZ, V. S.; SANTOS, T. L.; FROUFE, L. C. M. Corredores ecológicos como ferramenta para a desfragmentação de florestas tropicais. Pesquisa Florestal Brasileira, Colombo, PR, v. 30, n. 63, p. 207-16, ago./out. 2010. Disponível em: https://ainfo.cnptia.embrapa.br/digital/bitstream/item/25260/1/158-6954-PB.pdf. Acesso em: 15 jul. 2020.

SILVA, C. A. D. Determinação da dose de caulim eficiente contra o bicudo. In: CONGRESSO BRASILEIRO DE MAMONA, 6.; SIMPÓSIO INTERNACIONAL DE OLEAGINOSAS ENERGÉTICAS, 3., 2014, Fortaleza. Anais [...]. Campina Grande, PB: Embrapa Algodão, 2014. p. 108. Disponível em: https://ainfo.cnptia.embrapa. br/digital/bitstream/item/112127/1/FIT318-p108.pdf. Acesso em: 15 jul. 2020.

TETILA, E. C. Detecção e classificação de doenças e pragas da soja usando imagens de veículos aéreos não tripulados e técnicas de visão computacional. 2019. 103p. Tese (Doutorado em Desenvolvimento Local) - Universidade Católica Dom Bosco (UCDB), Campo Grande, MS, 2019.

TETILA, J. L. Meio ambiente: Mato Grosso do Sul em foco. Saarbrücken, Alemanha: Novas Edições Acadêmicas, 2017.

UNITED NATIONS. Department of Economic and Social Affairs, Population Division. World population prospects: the 2017 revision - key findings and advance tables. Working Paper n. ESA/P/WP/248, 2017. Disponível em: https://esa.un.org/unpd/wpp/Publications/Files/WPP2017_KeyFindings.pdf. Acesso em: 15 jul. 2020.

VALICENTE, F. H.; TUELHER, E. S. Controle biológico da lagarta do cartucho, Spodoptera frugiperda, com Baculovírus. Embrapa Milho e Sorgo, Sete Lagoas, MG, Circular Técnica 114, 2009.

VILELA, E. F. Adoção de feromônios no manejo integrado de pragas. Pesquisa Agropecuária Brasileira, Brasília, v. 27, s./n., p. 315-8, abr. 1992. Disponível em: https://ainfo.cnptia.embrapa.br/digital/bitstream/ Al-SEDE/20664/1/pab26_abresp_92.pdf. Acesso em: 15 jul. 2020.

WORLD HEALTH ORGANIZATION (WHO). The impact of pesticides on health: preventing intentional and unintentional deaths from pesticide poisoning. 2004. Disponível em: http://www.who.int/mental_health/ prevention/suicide/en/PesticidesHealth2.pdf. Acesso em: 15 jul. 2020.

ZAGO, V. C. P.; POLLI, H.; RUMJANEK, N. G. Pseudomonas spp. Fluorescentes - Bactérias promotoras de crescimento de plantas e biocontroladoras de fitopatógenos em sistemas de produção agrícola. Seropédica: Embrapa Agrobiologia, dez. 2000. 32 p. (Embrapa-CNPAB. Documentos, 127).

ZALLES, V. et al. Near doubling of Brazil's intensive row crop area since 2000. Proceedings of the National Academy of Sciences, v. 116, n. 2, p. 428-35, 2000.

\section{Sobre os autores:}

Everton Castelão Tetila: Doutor em Desenvolvimento Local com pesquisas em Visão Computacional pela Universidade Católica Dom Bosco (UCDB). Mestre em Engenharia de Produção pela 
Universidade Paulista (Unip). Graduado em Ciência da Computação pela Universidade Estadual de Mato Grosso do Sul (Uems). Professor do magistério superior nos cursos de Engenharia de Computação, Sistemas de Informação e Licenciatura em Computação na Universidade Federal da Grande Dourados (UFGD). Tem experiência na área de Ciência da Computação, com ênfase em Banco de Dados, Visão Computacional, Tecnologias da Informação e Comunicação (TICs) e Web Design. Vencedor do Prêmio Mercosul de Ciência e Tecnologia, Edição 2018, na categoria pesquisador sênior, com o trabalho "Uma abordagem de aprendizagem profunda para contagem automática de insetos-praga na soja". Revisor de periódicos internacionais de alto impacto: Sensors (ISSN 1424-8220) e Computer and Electronics in Agriculture (ISSN 0168-1699). Membro da Comissão de Avaliação de Cursos da SED/Fundect. E-mail: evertontetila@ufgd.edu.br, Orcid: http://orcid.org/0000-0001-5396-766X

José Laerte Cecílio Tetila: Mestre em Geografia Física pela Universidade de São Paulo (USP). Especialista em Geografia Física pela Faculdade Dom Bosco, de Santa Rosa, RS. Graduado em Geografia pela atual Universidade Católica Dom Bosco (UCDB). Em 2011, foi eleito deputado estadual. Na Assembleia Legislativa, atua em defesa dos Direitos Humanos, do meio ambiente, da agricultura familiar, do desenvolvimento sustentável e da população indígena. Presidente da Comissão de Trabalho, Cidadania e Direitos Humanos, foi o autor da lei que criou o Fundo Estadual para Aquisição de Terras Indígenas (Fepati), com a finalidade de captar recursos financeiros para aquisição de terras particulares em áreas indígenas. E-mail: Itetila@hotmail.com, Orcid: http://orcid.org/0000-0002-0321-3082

Hemerson Pistori: Pós-doutor pela University of Bristol, Inglaterra, com bolsa CNPq. Doutor em Engenharia Elétrica pela Universidade de São Paulo (USP). Mestre em Ciência da Computação pela Universidade Estadual de Campinas (Unicamp). Graduado em Ciência da Computação pela Universidade Federal de Mato Grosso do Sul (UFMS). Professor na Universidade Católica Dom Bosco (UCDB). Membro do conselho superior da Fundação de Amparo à Pesquisa (FAP) de Mato Grosso do Sul. E-mail: pistori@ucdb.br, Orcid: http://orcid.org/0000-0001-8181-760X

Maria Angélica Biroli Ferreira da Silva: Doutoranda em Desenvolvimento Local pela Universidade Católica Dom Bosco (UCDB). Mestre em Estudos Fronteiriços pela Universidade Federal de Mato Grosso do Sul, Campus do Pantanal (UFMS/Cpan). Pós-Graduação Lato Sensu em Direito Processual pela Faculdade Toledo de Ensino de Presidente Prudente, SP. Graduada em Direito pela Faculdade de Direito da Alta Paulista (FAP). Vice-presidente da OAB/MS - 1a Subseção de Corumbá. E-mail: angelica.ferreira@ufms.br, Orcid: http://orcid.org/0000-0002-3208-8284 